\title{
COMMUNICATIONS
}

\section{TRANSPORT ACROSS THE ISOLATED CILIARY BODY OF OX AND RABBIT*}

\author{
BY \\ D. F. COLE \\ Medical Research Council Ophthalmological Research Unit, Institute of Ophthalmology, \\ University of London
}

THE present paper deals with some electrical properties of the isolated ciliary body of the ox and the rabbit when various concentrations of anions and cations are present in the solutions on the inner (aqueous or epithelial) and outer (stromal) sides. There is evidence (Cole, 1960a, b; 1961a, b) that the ciliary body, like many other regions where there is a secretory epithelium, transports sodium ion actively in a determined direction by means of a relatively specific carrier (cf. Hokin and Hokin, 1960) or sodium "pump" (Ussing, 1960) energized from metabolic processes occurring within the epithelial cells. Such a transfer of sodium ions to the aqueous side of the blood-aqueous barrier would tend to create an electrical potential and so influence the passage of other ions. It would favour the migration of anions, such as chloride, to the aqueous side and this would, in its turn, tend to reduce the potential difference (P.D.) arising from sodium transport. The implications of these interactions have been worked out in considerable detail for frog skin by Linderholm $(1952,1954)$ and this treatment has been applied to the present problem.

As is shown below, it is possible to estimate the sodium and anion conductivities of the ciliary epithelium and the active transport potential of the sodium pump if measurements are made of the total electrical resistance of the membrane, the P.D. across it and the relationship of this P.D. to the activity of sodium ions in the solution on the stromal side. These measurements, together with values for the "short-circuit current" (Ussing and Zerahn, 1951) have been obtained using ox or rabbit ciliary bodies in vitro with various bathing media ( $c f$. Table I) on the outer (stromal) side.

TABLE I

COMPOSITION OF SALINE MEDIA (mEq (or mM) PER LITRE)

\begin{tabular}{l|r|r|r|r|r|r|r|r}
\hline Medium & $\mathrm{Na}$ & $\mathrm{Cl}$ & $\mathrm{K}$ & $\mathrm{Mg}$ & $\mathrm{SO}_{4}$ & Glucose & Glutamate & $\begin{array}{c}\text { *Tris/Nitric Acid Buffer at } \\
\mathrm{pH} 7.45\end{array}$ \\
\hline "NaCl" & 150 & 150 & 3.0 & 0.9 & 0.9 & 7.0 & 10.0 & 15.4 \\
\hline "SO $4 "$ & 150 & 0 & 3.0 & 0.9 & 76.0 & 7.0 & 10.0 & 15.4 \\
\hline "Mannitol" & 0 & 0 & 3.0 & 0.9 & 0.9 & 7.0 & 10.0 & 15.4 \\
\hline
\end{tabular}

* "Tris" stands for tris (hydroxymethyl) aminomethane 
In some cases a large proportion of the chloride in the outer solution was replaced by sulphate using the " $\mathrm{SO}_{4}$ " medium whilst in another series both the sodium and chloride ions were largely replaced by mannitol.

A less indirect estimate of the net movement of sodium ions through the isolated blood-aqueous barrier has also been made by measuring the influx rate of water from the stromal to the epithelial side and calculating the corresponding sodium influx on the assumption that the transfer is isosmotic (Cole, 1960b).

\section{Material and Methods}

The method used for the study of the ox ciliary body in vitro has already been described in some detail (Cole, 1961b), and the same technique was used in the present series of experiments for measuring membrane P.D. and resistance. The current flowing across the ciliary body when the P.D. was held at zero (i.e. the shortcircuit current) was measured directly by manually adjusting the current from an external source until the two sides of the membrane were equipotential.

When using rabbit ciliary body, the problem raised by the small size of the preparation was overcome by modifying the original apparatus, introducing two micro-cells, shown at $\mathrm{N}$ and $\mathrm{P}$, Fig. 1 (opposite), the whole being constructed of "Perspex".

The anterior segment of a freshly-excised eye was removed by a circular incision some $3 \mathrm{~mm}$. behind the limbus and the lens and remaining pieces of vitreous carefully dissected away. With the preparation placed corneal side downwards, the sclera was grasped firmly at one point with toothed capsule forceps and a blunt probe (iris repositor) inserted in the plane of separation between the anterior part of the retina and the sclera. This was pushed forwards and slightly downwards to pass between the ciliary body and the corneo-scleral junction and then laterally, away from the forceps, to extend the cleavage around the circumference of the preparation. This circumferential separation was repeated several times, shifting the position of the forceps in each case, until the ciliary body and iris were entirely freed from the corneo-scleral junction. This preparation was then placed on a piece of "Terylene" gauze with the posterior iridic surface and ciliary processes uppermost and the pupil was occluded by placing a cellulose disc $0.75 \mathrm{~cm}$. diameter $\left(F_{2}\right.$, Fig. 1) on the posterior surface of the iris. The iris-ciliary body was then mounted in the micro-cell, so that the anterior surface of the iris was covered by a second cellulose disc, $F_{1}$, lying on the central pillar, $M_{1}$, of the outer (stromal) compartment, and so that the annular space between the pillar and the edge of the micro-cell was covered by the stromal surface of the ciliary body. The second micro-cell, P, was placed in position, and the two were pressed closely together and mounted as shown in Fig. 1. The membrane P.D. was measured between the two electrodes, A, which were connected to the solution on each side of the membrane through a drop of potassium chloride solution, $\mathrm{B}$, lying on top of two agar- $\mathrm{NaCl}$ bridges, C. Asymmetry potentials were backed off in a preliminary stage before the tissue was mounted. Current from an external source could be applied via the electrodes $\mathrm{J}$ and $\mathrm{K}$, and the short-circuit current was taken to be the current in $\mu \mathrm{A}$ flowing in this external circuit, and hence between $\mathrm{J}$ and $\mathrm{K}$, when the membrane P.D. was reduced to zero by manipulating the controls of the external current 


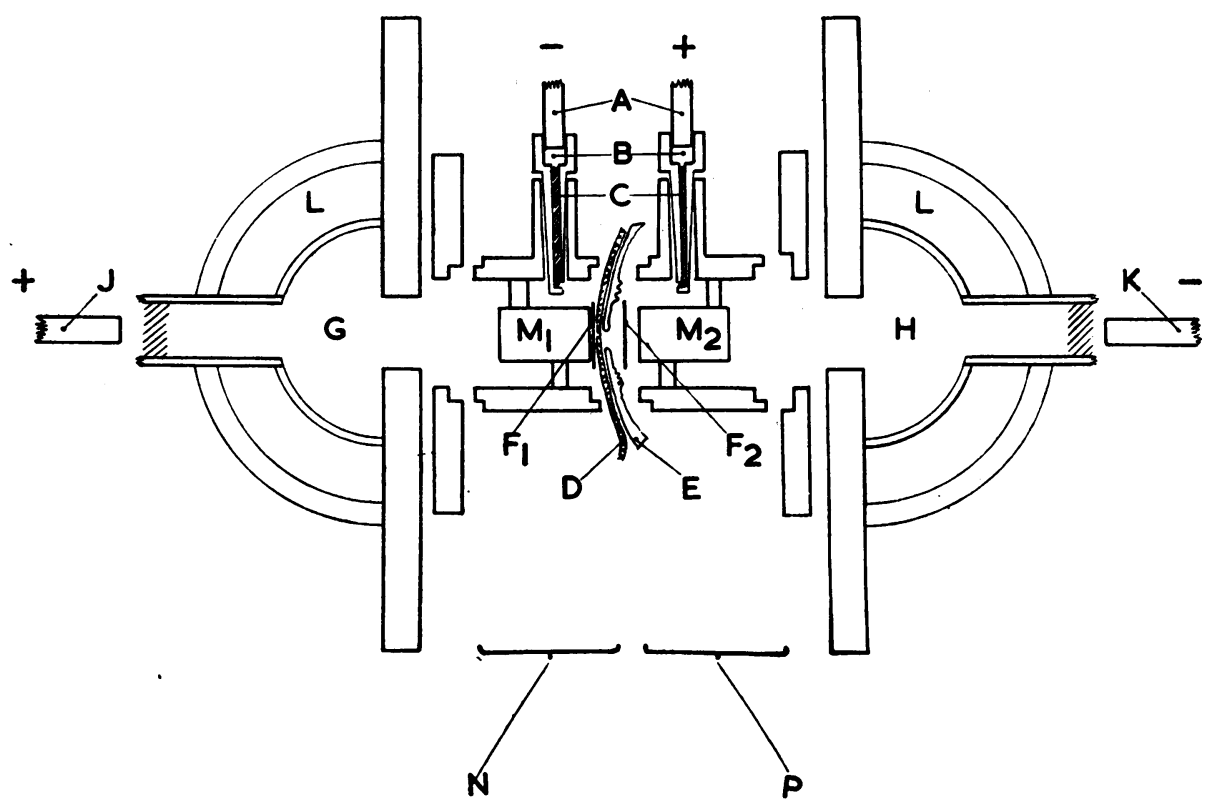

Fig. 1.-Apparatus for measurement of membrane potential, resistance, and short-circuit current in isolated rabbit ciliary body.
B $\quad 3.0 \mathrm{M}$ potassium chloride solution.
Electrodes for measuring potential difference.
C Agar- $\mathrm{NaCl}$ bridges.
D "Terylene" gauze covering stromal surface of ciliary body.
E Isolated rabbit ciliary body, stromal surface facing micro-cell $\mathrm{N}$, and neuro- epithelial surface facing micro-cell $\mathbf{P}$.
$F_{1}, F_{2} \quad$ Cellulose discs occluding pupil.
G, $\mathbf{H}$ Chambers for saline media (oxygenated), $\mathbf{G}$ being the chamber corresponding to the stromal side of the tissue.
J, $\mathrm{K}$ Connexions (via agar-NaCl bridges) to external current source used for measur- ing resistance and short-circuit current.
L Water-jacket maintained at $44^{\circ} \mathrm{C}$
$\mathbf{M}_{1}, \mathbf{M}_{2}$ Central pillars of the two micro-cells supporting the isolated tissue and assisting to occlude the pupil.
N Micro-cell (stromal side).
P Micro-cell (neuro-epithelial side).

source. . By altering the external current and observing the change in membrane potential, values for total membrane resistance were obtained and these were finally expressed as conductances per $\mathrm{cm} .^{2}$ of exposed ciliary body in $\mathrm{k} \Omega^{-1} \cdot \mathrm{cm} .^{-2}$. The area exposed, taken as the area corresponding to the inside diameter of the micro-cells $\left(1 \cdot 15 \mathrm{~cm}\right.$.) minus the area of the celluloid discs, was equal to $0.60 \mathrm{~cm}^{2}$. Circulating water from a tank maintained at $44^{\circ} \mathrm{C}$. was found to give a steady temperature of $37^{\circ} \mathrm{C}$. in the vicinity of the ciliary body. The membrane P.D. at A (Fig. 1) was measured with a model 33B "Vibron" electrometer having an input impedance of $10^{13} \Omega$, and recordings were made as described in an earlier paper (Cole, 1961a).

When "mannitol" medium or " $\mathrm{SO}_{4}$ " medium was substituted for " $\mathrm{NaCl}$ " medium in the outer compartment, this was effected in the experiments with ox ciliary body simply by removing the one solution with a syringe and replacing it by 
the other, this being repeated two or three times before any electrical measurements were made. In the rabbit experiments, the micro-cell, N (Fig. 1), had two side arms, not shown in the diagram, and substitution was effected by running in the appropriate medium (previously warmed to $37^{\circ} \mathrm{C}$.) through one of these, the other serving as an overflow. Between 30 and $50 \mathrm{ml}$. were allowed to flow through the micro-cell before measurements were made. In both ox and rabbit experiments the solutions in the main compartments, $G$ and $H$, were continuously stirred by bubbling oxygen through and samples were taken before and after the electrical measurements for estimation of sodium and chloride concentration.

In order to determine the regression coefficient, B, between sodium concentration in the outer (stromal) compartment and the membrane potential, the sodium concentration was reduced by adding suitable proportions of "mannitol" medium to the "NaCl" (or " $\mathrm{SO}_{4}$ ") medium already in the compartment. In the experiments where " $\mathrm{NaCl}$ " medium in the outer compartment was replaced by "mannitol" medium, the range of sodium concentrations actually observed was sufficient to enable the regression coefficient of potential with concentration to be estimated.
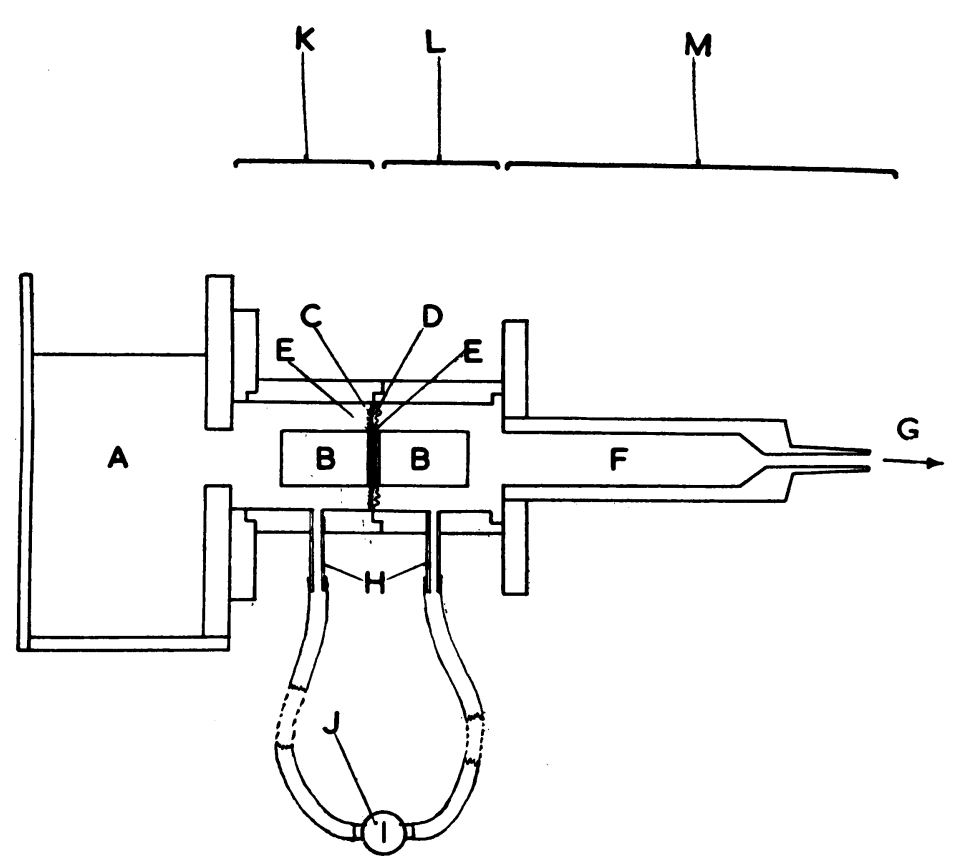

FIG. 2.-Apparatus for measurement of water influx (detail).

\footnotetext{
A Chamber (stromal side) for oxygenated saline media. This chamber is surrounded by a water-jacket (not shown) and maintained at $44^{\circ} \mathrm{C}$. It corresponds to G (Fig. 1).

B Central pillars of the two micro-cells, $K$ and $L$.

C Terylene gauze on stromal side of tissue.

E Cellulose discs occluding pupil.

F, G Tube on neuro-epithelial side of tissue leading to measuring capillary shown in Fig. 3.

H Side-arms to micro-cells which communicate with each other via tap, J.

K, L Micro-cells, stromal and neuro-epithelial sides respectively.

$\mathrm{M}$ Connexion to measuring capillary.
} 
Flow Measurements.-The net water flux from stromal.to epithelial side was measured in the isolated rabbit ciliary body, using the apparatus shown in Figs 2 and 3. After removal from the eye as before, the ciliary body was placed between the two micro-cells ( $\mathrm{K}$ and L, Fig. 2), extreme care being taken to occlude the pupil with a lightly-greased celluloid disc on each side (E and $E^{\prime}$, Fig. 2). The two micro-cells were clamped between the water-jacketed chamber, A, and the tube, $\mathrm{F}$, and each side was filled with " $\mathrm{NaCl}$ " medium, care being exercised to avoid including air bubbles. That part of the apparatus shown in detail in Fig. 2 was connected by its outlet, G, to the remainder of the apparatus (as shown in Fig. 3) by means of polythene tubing. During this operation the tap (J, Fig. 2; F, Fig. 3) connecting the two micro-cells was kept open. The water flux was estimated from the excursion of the meniscus in the capillary-tube, $\mathrm{K}$ (Fig. 3), measured by means of a low-power microscope with a micrometer eye-piece, $L$. The capillary could also be connected with a reservoir, $J$, in order to re-set the meniscus, and was mounted on a mechanical stage (not shown) which served as a

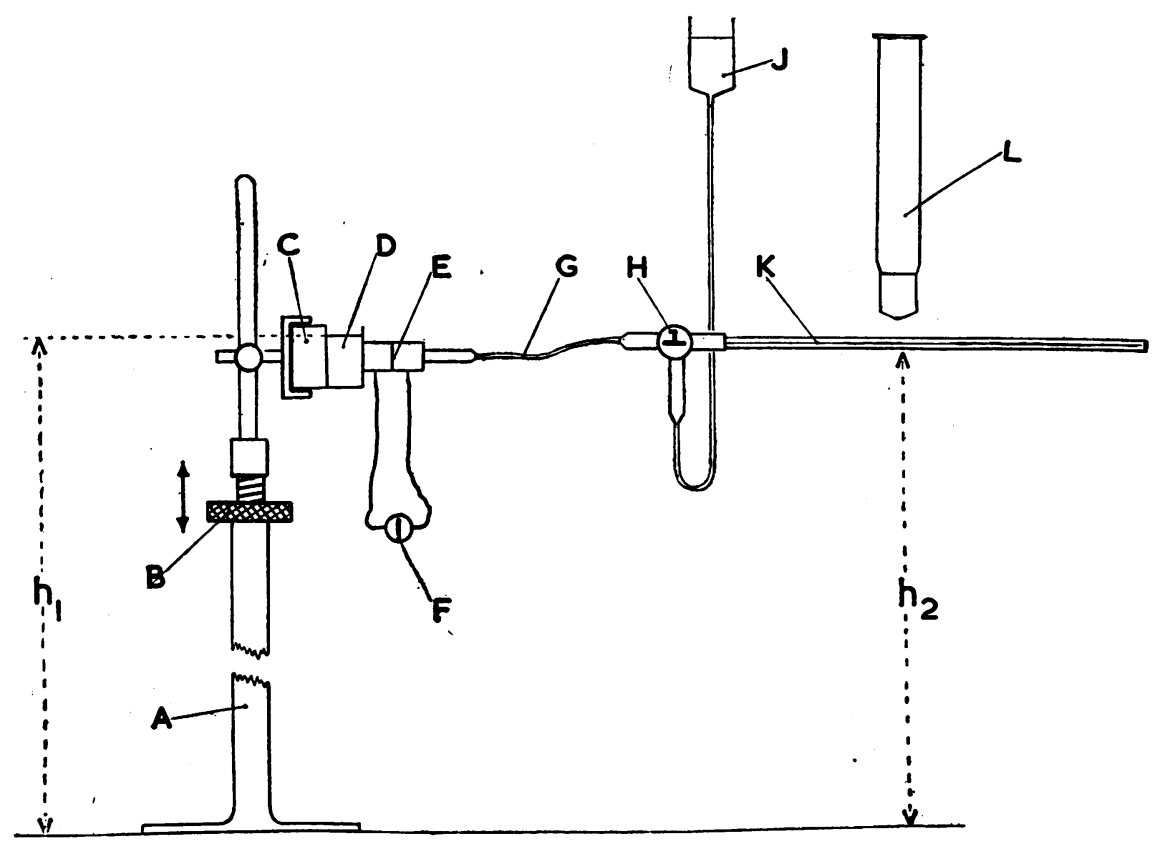

FIG. 3.-Apparatus for measurement of water influx (diagrammatic).
A Stand for chamber and micro-cells.
B Adjusting screw for height of fluid level in chamber $D\left(h_{1}\right)$.
C Water-jacket at $44^{\circ} \mathrm{C}$.
D Chamber containing oxygenated medium on stromal side of tissue.
E Position of isolated tissue between the two micro-cells.
F Tap connecting micro-cells.
G Polythene tubing connecting the fluid on the neuro-epithelial side of the tissue with the measuring capillary, $K$.
H Three-way tap.
J Fluid reservoir for adjusting fluid in capillary.
K Measuring capillary at a height, $h_{2}$, above level of bench.
L Low-power microscope with micrometer eyepiece. 
fine-adjustment. Before using the apparatus for actual measurements and with the tap, $F$, open, the height $\left(h_{1}\right)$ of the fluid in $D$ above the bench was adjusted by means of the screw, B, so that there was no movement of fluid into or out of the capillary. The meniscus was then set at a suitable point in the capillary, the threeway tap, $H$, was set to connect the micro-cell with the capillary, the tap, $F$, was closed, and the excursion of the meniscus was measured for known intervals of time.

The temperature at $\mathrm{E}$ was reduced to about $10^{\circ} \mathrm{C}$. in some experiments by running ice-water through the water- jacket, $\mathrm{C}$. Other experiments were conducted using either " $\mathrm{SO}_{4}$ " medium or "mannitol" medium on the stromal side of the preparation and " $\mathrm{NaCl}$ " medium on the epithelial side.

Because of the need to be certain that the pupil was occluded, a series of celluloid discs of different sizes was available and, although the annular area of ciliary body available for water movement varied from one preparation to another, the values shown in Table II are calculated in terms of $\mu 1 . \mathrm{min}^{-1} \mathrm{~cm} .^{-2}$.

Chemical Methods.-Sodium was estimated by flame photometry and chloride by the method of Bertolacini and Barney (1958).

\section{Results}

Experimentally determined values for both ox and rabbit ciliary body are given in Table II. The change in P.D. resulting from altering the composition of the fluid on the stromal side of the tissue took between 3 and $10 \mathrm{~min}$.

TABLE II

OBSERVED VALUES FOR SHORT-CIRCUIT CURRENT, POTENTIAL, AND CONDUCTANCE IN OX AND RABBIT CILIARY BODIES

\begin{tabular}{|c|c|c|c|c|c|c|}
\hline Eye & Observations & $\begin{array}{l}\text { “NaCl” } \\
\text { Medium }\end{array}$ & $\begin{array}{l}\text { "SOQ", } \\
\text { Medium }\end{array}$ & Change & $\begin{array}{l}\text { "Mannitol" } \\
\text { Medium }\end{array}$ & Change \\
\hline \multirow{5}{*}{ Ox } & $I\left(\mu \mathrm{A} . \mathrm{cm}^{-2}\right)$ & $\begin{array}{r}46.0 \\
\pm 2.9\end{array}$ & $\begin{array}{r}47.8 \\
\pm 6.3\end{array}$ & $\begin{array}{l}+1.8 \\
\pm 4.4\end{array}$ & $\begin{array}{r}19.1 \\
\pm 6.5\end{array}$ & $\begin{array}{l}-26.0 \\
\pm 3.4\end{array}$ \\
\hline & $\phi(\mathrm{mV})$ & $\begin{array}{r}5.53 \\
\pm 0.41\end{array}$ & $\begin{array}{r}7.71 \\
\pm 0.47\end{array}$ & $\begin{array}{l}+2.18 \\
\pm 0.36\end{array}$ & $\begin{array}{r}3.11 \\
\pm 0.5\end{array}$ & $\begin{array}{l}-2.54 \\
\pm 0.23\end{array}$ \\
\hline & $G\left(k \Omega^{-1} \cdot \mathrm{cm} \cdot^{-2}\right)$ & $\begin{array}{r}8.63 \\
\pm 0.95\end{array}$ & $\begin{array}{r}7.63 \\
\pm 0.74\end{array}$ & $\begin{array}{l}-1.00 \\
\pm 0.49\end{array}$ & $\begin{array}{r}5.72 \\
\pm 0.70\end{array}$ & $\begin{array}{l}-3.90 \\
\pm 0.40\end{array}$ \\
\hline & B (where $\left.\phi=A+B \cdot \log \cdot a_{1}\right)$ & $4 \cdot 50$ & 4.62 & & $4 \cdot 55$ & \\
\hline & Range of $a_{1}(\mathrm{mEq} / \mathrm{l})$. & $98-158$ & $123-157$ & & $15-35 \cdot 5$ & \\
\hline \multirow{6}{*}{ Rabbit } & $I\left(\mu \mathrm{A} . \mathrm{cm}^{-2}\right)$ & $\begin{array}{c}29.5 \\
\pm 0.42\end{array}$ & $\begin{array}{c}29 \cdot 0 \\
\pm 1 \cdot 76\end{array}$ & $\begin{array}{l}-0.7 \\
\pm 1.5\end{array}$ & $\begin{array}{r}13.5 \\
\pm 3.5\end{array}$ & $\begin{array}{l}-17 \cdot 0 \\
\pm 3 \cdot 2\end{array}$ \\
\hline & $\phi(\mathrm{mV})$ & $\begin{array}{r}3.83 \\
\pm 0.16\end{array}$ & $\begin{array}{r}5.97 \\
+0.23\end{array}$ & $\begin{array}{l}+2.15 \\
\pm 0.21\end{array}$ & $\begin{array}{r}1.03 \\
\pm 0.32\end{array}$ & $\begin{array}{l}-2.80 \\
\pm 0.35\end{array}$ \\
\hline & $G\left(\mathrm{k} \Omega^{-1} \mathrm{~cm} \cdot \cdot^{-2}\right)$ & $\begin{array}{r}8.09 \\
\pm 0.29\end{array}$ & $\begin{array}{r}7.03 \\
\pm 0.45\end{array}$ & $\begin{array}{l}-1.05 \\
\pm 0.47\end{array}$ & $\begin{array}{r}5.35 \\
\pm 0.68\end{array}$ & $\begin{array}{l}-2.64 \\
\pm 0.54\end{array}$ \\
\hline & B (where $\left.\phi=A+B . \log . a_{1}\right)$ & $5 \cdot 17$ & $5 \cdot 23$ & & $5 \cdot 10$ & \\
\hline & Range of $a_{1}(\mathrm{mEq} / 1)$. & $100-162$ & $133-156 \cdot 7$ & & $17 \cdot 5-36 \cdot 4$ & \\
\hline & Water Influx $\left(\mu 1 . \min ^{-1} \mathrm{~cm} .^{-2}\right)$ & $\begin{array}{r}0.16 \\
\pm 0.02\end{array}$ & $\begin{array}{r}0.16 \\
\pm 0.02\end{array}$ & 0 & $\begin{array}{r}0.072 \\
\pm 0.01\end{array}$ & $\begin{array}{r}-0.088 \\
\pm 0.013\end{array}$ \\
\hline
\end{tabular}

The values given are means \pm the standard error of the mean. Each mean is derived from at least ten experimental results. 
to reach its final value and thereafter remained stable for at least $15 \mathrm{~min}$. (Fig. 4).

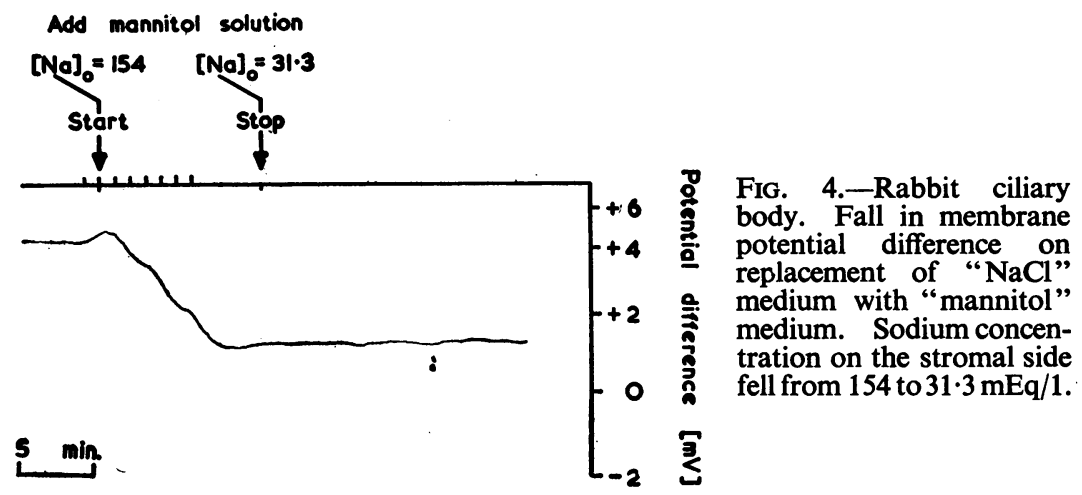

Repeated determinations of short-circuit current on the same tissue gave consistent values and, although they decreased with "mannitol" medium on the stromal side, returned to normal when this was replaced with " $\mathrm{NaCl}$ " medium (Fig. 5).

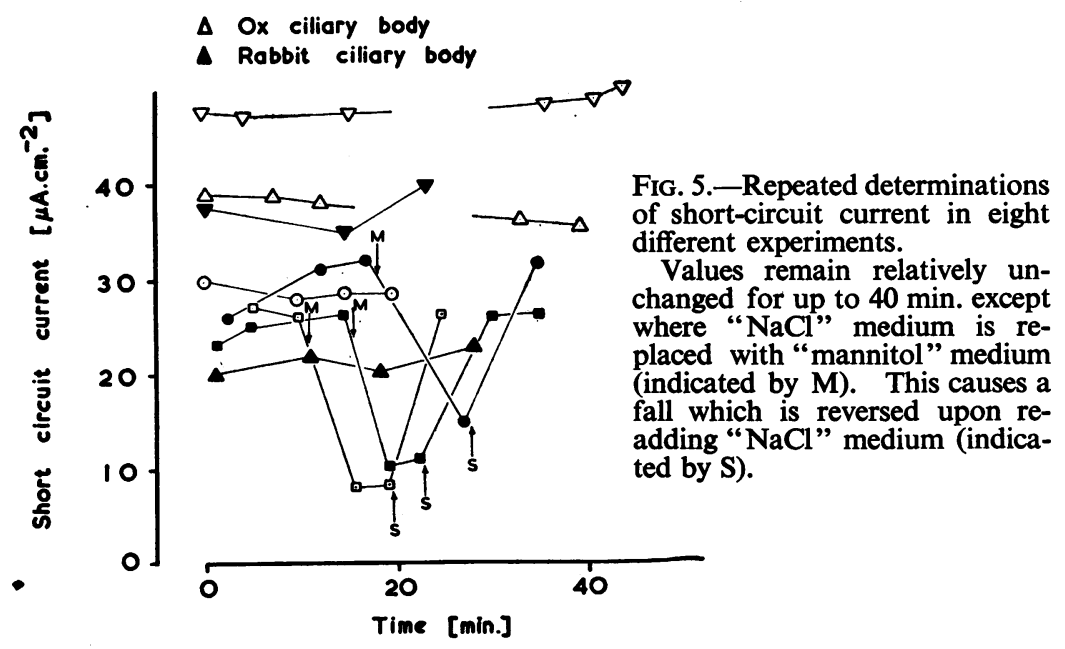

These experimental values were used to derive calculated estimates for ion conductances and the active sodium transport potential, following the treatment elaborated by Linderholm (1952). For this purpose the sodium flux across the membrane is assumed to consist of an active and a passive component, the active component being the flux due to an intra-cellular sodium transporting potential, $\phi_{a}^{\mathrm{Na}}$, operating against a partial conductance, $\mathrm{G}_{a}^{\mathrm{Na}}$, whilst the passive component is the flux due to the electrochemical potential gradient across the membrane whose partial sodium conductance is $\mathrm{G}_{p}^{\mathrm{Na}}$. In the case where there is active transport from Side 1 to Side 2 and 
the sodium activities on the outer (stromal) side and the inner (epithelial) side are $a_{1}$ and $a_{2}$ respectively, and where the membrane P.D. is $\phi$ (the potential on Side 1 being taken as zero), the electrochemical potential gradient between Side 1 and Side 2 is a function of:

$$
\frac{\mathrm{RT}}{\mathrm{F}} \ln \cdot \frac{a_{1}}{a_{2}}-\phi
$$

$R, T$, and $F$ having their usual significance.

This gradient applies to both active and passive sodium flux, so that in the case of the active flux the total driving potential is:

$$
\phi_{a}^{\mathrm{Na}}-\phi+\frac{\mathrm{RT}}{\mathrm{F}} \ln \cdot \frac{a_{1}}{a_{2}} \text { into a conductance } \mathrm{G}_{a}^{\mathrm{Na}} \text {, while in the case of the }
$$
passive flux it is $\frac{\mathrm{RT}}{\mathrm{F}} \ln \cdot \frac{a_{1}}{a_{2}}-\phi$ into a conductance $\mathrm{G}_{p}^{\mathrm{Na}}$.

The positive potential on Side 2, because of active inwardly directed sodium transport, also tends to favour a net influx of anion, the driving potential being: $\frac{\mathrm{RT}}{\mathrm{F}} l n \cdot \frac{a_{1}}{a_{2}}+\phi$ into an anion conductance, $\mathrm{G}^{\mathrm{An}}$. In the subsequent treatment it is assumed that $\mathrm{G}^{\mathrm{Na}}=\mathrm{G}_{p}^{\mathrm{Na}}+\mathrm{G}_{a}^{\mathrm{Na}}$ and that the total membrane conductance, $\mathrm{G}$, is equal to $\mathrm{G}^{\mathrm{Na}}+\mathrm{G}^{\mathrm{An}}$.

Linderholm (1952: equation 1.5.3) has derived an expression relating the membrane P.D. to the active sodium transport potential, the ion conductivities, and sodium activities, and the external current, $I$, produced by the system:

$$
\phi=\frac{\mathrm{G}^{\mathrm{Na}} \phi_{a}^{\mathrm{Na}}-\left(\mathrm{G}^{\mathrm{Na}}-\mathrm{G}^{\mathrm{An}}\right)\left(\frac{\mathrm{RT}}{\mathrm{F}} \ln \cdot \frac{a_{2}}{a_{1}}\right)}{\left(\mathrm{G}^{\mathrm{Na}}+\mathrm{G}^{\mathrm{An}}\right)}-I \quad . \quad .
$$

If $I=0$, as in the present case where the external circuit is not connected, and the concentration of sodium on the stromal side (Side 1) is altered without altering the inside concentration, the expression becomes:

$$
\phi=\frac{\mathrm{G}^{\mathrm{Na}} \phi_{a}^{\mathrm{Na}}-\left(\mathrm{G}^{\mathrm{Na}}-\mathrm{G}^{\mathrm{An}}\right) 60 \log . a_{2}}{\left(\mathrm{G}^{\mathrm{Na}}+\mathrm{G}^{\mathrm{An}}\right)}+\frac{\left(\mathrm{G}^{\mathrm{Na}}-\mathrm{G}^{\mathrm{An}}\right) 60 \log \cdot a_{1}}{\left(\mathrm{G}^{\mathrm{Na}}+\mathrm{G}^{\mathrm{An}}\right)} .
$$

(reverting to common logarithms and a corresponding approximate value for $\frac{R T}{F}$ ) if it is taken as a first approximation that $G^{\mathrm{Na}}$ and $\mathrm{G}^{\mathrm{An}}$ are constant. Since the whole of the first term in (2) is constant, the linear regression of $\phi$ with log. $a_{1}$ is $\frac{\left(\mathrm{G}^{\mathrm{Na}}-\mathrm{G}^{\mathrm{An}}\right)}{\left(\mathrm{G}^{\mathrm{Na}}+\mathrm{G}^{\mathrm{An}}\right)} \times 60$, and is equal to the constant $\mathrm{B}$ in the regression equation $\phi=\mathrm{A}+\mathrm{B} \log a_{1}$. Since the total conductance $\mathrm{G}=\mathrm{G}^{\mathrm{Na}}+\mathrm{G}^{\mathrm{An}}$ is measured directly as described above, both $\mathrm{G}^{\mathrm{Na}}$ and $\mathrm{G}^{\mathrm{An}}$ may be calculated and also $\phi_{a}^{\mathrm{Na}}$, which is obtained by substituting in (1) or (2). The fact that 
there is a linear relationship between membrane P.D. and log. $a_{1}$ over a wide range of concentrations (Cole, 1961b) goes some way to justifying the approximation entailed in regarding $\mathrm{G}^{\mathrm{Na}}$ and $\mathrm{G}^{\mathrm{An}}$ as constant over a small range.

Values for the "active" and "passive" conductances, $\mathrm{G}_{a}^{\mathrm{Na}}$ and $\mathrm{G}_{p}^{\mathrm{Na}}$ can only be derived by making further assumptions:

(i) That anion conductance is not distinguished from chloride ion conductance,

(ii) That the ratio of ionic mobilities of sodium and chloride in the membrane is the same as the ratio in water, i.e. that the value for $\frac{u_{\mathrm{Na}}}{u_{\mathrm{Cl}}}$ in the tissue, ignoring concentration effects, should bé approximately 0.66 (cf. Robinson and Stokes, 1959).

If these assumptions are made, then $\mathrm{G}_{p}^{\mathrm{Na}}=0.66 \mathrm{G}^{\mathrm{An}}$ and, since $\mathrm{G}^{\mathrm{An}}$ is known, both $G_{p}^{\mathrm{Na}}$ and $\mathrm{G}_{a}^{\mathrm{Na}}$ can be calculated. This entails an error depending on the divergence from unity of the ratio $\frac{\left(u_{\mathrm{Na}} / u_{\mathrm{Cl}}\right) \text { membrane }}{\left(u_{\mathrm{Na}} / u_{\mathrm{Cl}}\right) \text { water }}$, and on the extent to which ions other than chloride contribute to anion conductance. In the case where sulphate carries some of the anion current it seems that this error may be small since $\frac{u_{\mathrm{Na}}}{u_{\mathrm{SO}}}$ is approximately 0.628 , and the error would be at most 5 per cent. even if no chloride contributed to the anion conductance. In this extreme instance $\mathrm{G}_{p}^{\mathrm{Na}}$ would be overestimated and $\mathrm{G}_{a}^{\mathrm{Na}}$ underestimated.

The potential of the sodium "pump" $\left(E_{\mathrm{Na}}\right)$, as distinct from the available active sodium transport potential, $\phi_{a}^{\mathrm{Na}}$ depends upon the "internal" resistance (or conductance) of the pump, $G_{a}^{\mathrm{Na}}$, and the total sodium conductance of the tissue, $\mathrm{G}^{\mathrm{Na}}$ :

$$
E_{\mathrm{Na}}=\frac{\left(\mathrm{G}_{a}^{\mathrm{Na}}+\mathrm{G}_{p}^{\mathrm{Na}}\right) \phi_{a}^{\mathrm{Na}}}{\mathrm{G}_{a}^{\mathrm{Na}}}
$$

(Linderholm, 1952, 1954). It must be borne in mind, however, that the value so obtained for $E_{\mathrm{Na}}$ includes all the errors resulting from the foregoing assumptions.

\section{Discussion}

Short-circuit Current and Water Influx.-From work of Ussing and Zerahn (1951), Ussing (1960), Leaf and Renshaw (1957), and Leaf (1960) with amphibian tissues, it would appear that the epithelial membrane current at zero P.D., the "short-circuit current" (i.e. the value of $I$ in equation (1) when $\phi$ is zero), measures the rate of active sodium transport. Since this active cation transport would also be a determinant of net anion influx and because, in the formation of aqueous, the transport of solutes appears to be 
approximately isosmotic (Cole, 1960b), it follows that, apart from hydrostatic pressure differences, active transport should be the main determinant of net water influx across the ciliary epithelium. The net rate of transfer of fluid from stromal to epithelial sides, as estimated directly in isolated rabbit ciliary body, gave a mean value of $0.16 \mu 1 . / \mathrm{min} . \mathrm{cm} .^{-2}$ which, assuming the transfer to be isosmotic in the sense that

$$
-\frac{\left[\frac{d}{d t}\left(m_{1}\right)\right]}{\left[\frac{d}{d t}\left(v_{1}\right)\right]}=\bar{c}_{1}=\bar{c}_{2}
$$

(where $m_{1}$ is the amount of solute and $v_{1}$ the amount of solvent in the outer compartment and $\bar{c}_{1}$ and $\bar{c}_{2}$ are the mean concentrations in the outer and inner compartments respectively), implies a net sodium influx of $0.0246 \mu \mathrm{Eq}$. min..$^{-1} \mathrm{~cm}^{-2}$ and a corresponding short-circuit current of 35.6 $\mu \mathrm{A}$. $\mathrm{cm}^{-2}$. This is in reasonable agreement with the direct estimates of $I$ (Table II) and it can furthermore be shown that the water influx diminishes considerably when the preparation is cooled (Fig. 6) as would be anticipated if it were determined by the active sodium transport. Again, both shortcircuit current and influx rate of water undergo comparable reductions when "mannitol" medium is substituted for " $\mathrm{NaCl}$ " medium on the stromal side (Table II). From these results it is reasonable to assume that the shortcircuit current is proportional to and gives a reasonable measure of the active transport of sodium under the present conditions.

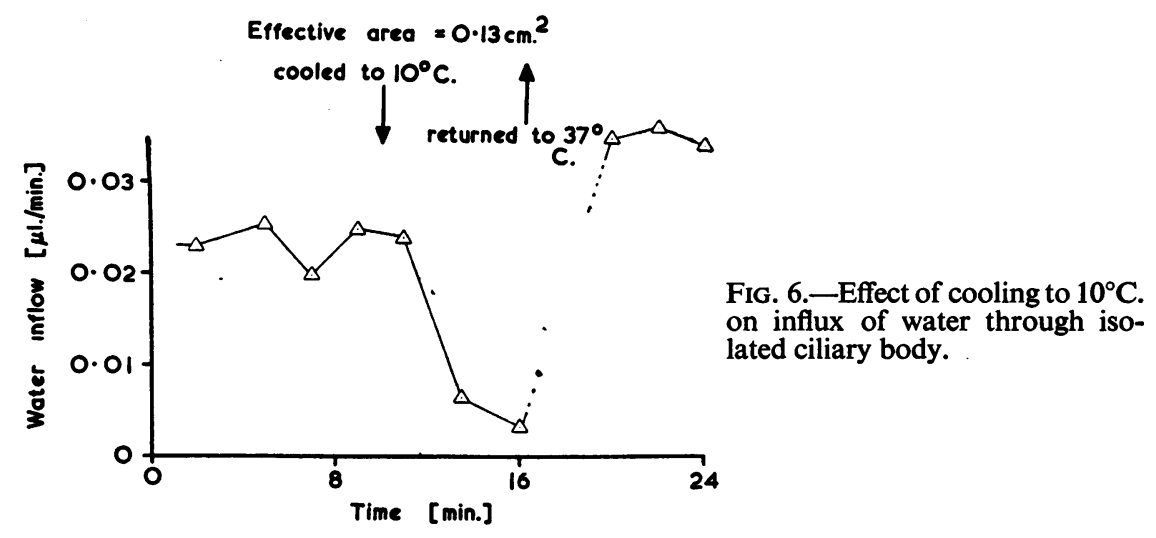

\section{Conductances}

" $\mathrm{NaCl}$ " Medium Outside.-From Tables II and III (opposite) it is evident that the ion conductances in the ciliary body are considerably greater than are the values found by Linderholm (1952) for frog skin. However, the present figures are given in terms of $\mathrm{cm}^{2}$ of exposed ciliary body and, on account of its extensive folding one $\mathrm{cm} .^{2}$ of ciliary body will have an effective epithelial surface area greater than this ( $c f$. Baurmann, 1930). Were this taken into 
TABLE III

CALCULATED PARAMETERS FOR ION CONDUCTANCES AND ACTIVE TRANSPORT POTENTIALS IN OX AND RABBIT CILIARY BODIES

\begin{tabular}{|c|c|c|c|c|}
\hline \multirow{2}{*}{\multicolumn{2}{|c|}{ Eye }} & \multicolumn{3}{|c|}{ Medium } \\
\hline & & “NaCl” & "SO $4 "$ & "Mannitol" \\
\hline \multirow{6}{*}{ Ox } & GNa & $4 \cdot 65$ & $4 \cdot 10$ & 3.03 \\
\hline & GAn & 4.00 & $3 \cdot 53$ & $2 \cdot 69$ \\
\hline & $\mathrm{G}_{p}^{\mathrm{Na}}$ & $2 \cdot 64$ & $2 \cdot 33$ & $1 \cdot 78$ \\
\hline & $\mathrm{G}_{a}^{\mathrm{Na}}$ & $2 \cdot 10$ & $1 \cdot 77$ & $1 \cdot 25$ \\
\hline & $\phi_{a}^{\mathrm{Na}}$ & $10 \cdot 3$ & $13 \cdot 3$ & $10 \cdot 6$ \\
\hline & $E_{\mathrm{Na}}$ & $33 \cdot 8$ & $30 \cdot 8$ & $36 \cdot 0$ \\
\hline \multirow{6}{*}{ Rabbit } & GNa & $4 \cdot 39$ & $3 \cdot 88$ & $2 \cdot 90$ \\
\hline & GAn & $3 \cdot 70$ & $3 \cdot 15$ & $2 \cdot 45$ \\
\hline & $\mathrm{G}_{p}^{\mathrm{Na}}$ & $2 \cdot 44$ & $2 \cdot 08$ & $1 \cdot 61$ \\
\hline & $\mathrm{G}_{a}^{\mathrm{Na}}$ & 1.95 & $1 \cdot 80$ & $1 \cdot 29$ \\
\hline & $\phi_{a}^{\mathrm{Na}}$ & 8.91 & $12 \cdot 8$ & $7 \cdot 20$ \\
\hline & $E_{\mathrm{Na}}$ & $27 \cdot 0$ & $29 \cdot 7$ & $30 \cdot 5$ \\
\hline
\end{tabular}

Values for conductances are given in $\mathrm{k} \Omega^{-1} \mathrm{~cm} .^{-2}$ and for potentials in $\mathrm{mV}$.

account, the values for conductance would be decreased and those for short-circuit current increased. In all cases the conductance of the sodium "pump" contributes rather less than 50 per cent. to the total sodium conductance.

" $\mathrm{SO}_{4}$ " Medium Outside.-When sulphate, as $\mathrm{Na}_{2} \mathrm{SO}_{4}$, was substituted for sodium chloride on the stromal side of the barrier, the sodium concentration was unaltered and, as a first approximation, $\frac{a_{2}}{a_{1}}$ could be regarded as 1 . The membrane P.D. $\phi$ increased, the total conductance fell (Table II), and there was a decrease in the calculated value of $G^{A n}$ and $G^{\mathrm{Na}}$ (Table III). The remaining anion conductance (the decrease being only some $12-15$ per cent.) may be due either to chloride conductance alone, since the tissue chloride is not completely replaced by sulphate and the average chloride concentration remaining on the stromal side was $25 \mathrm{mEq} / 1$., or alternatively to a fraction of the anion current being carried by sulphate ions which penetrated the barrier more slowly than chloride. This latter possibility is supported by the finding that a greater reduction of $\mathrm{G}^{\mathrm{An}}$ occurred when the " $\mathrm{NaCl}$ " medium 
was replaced by "mannitol" medium on the stromal side despite the fact that the final chloride was again $25 \mathrm{mEq} / 1$., as with the " $\mathrm{SO}_{4}$ " medium. If sulphate were to contribute significantly to anion conductance it would be in accord with the generally higher permeability of ciliary epithelium as compared with frog-skin and with the fact that increase of membrane potential caused by replacing chloride with sulphate is less marked in ciliary body. An increase, amounting to $16 \mathrm{mV}$, has been observed in the P.D. between the renal tubular lumen and the peritubular fluid in Necturus when sulphate is substituted for chloride in the lumen (Giebisch, 1961) and, like the increase of P.D. across the ciliary body, is considerably less than the increases observed in frog skin (Koefoed-Johnsen and Ussing, 1956, 1958; Ussing, 1960). An estimate of the value for $\mathrm{G}^{\mathrm{Cl}}$ in Giebisch's experiments, calculated from his determinations of chloride flux and P.D. (Giebisch, 1960), gives $\mathrm{G}^{\mathrm{Cl}}=0.217 \mathrm{k} \Omega^{-1} \mathrm{~cm} .^{-2}$, in agreement with the results of Whittembury, Sugino, and Solomon (1961). This value for Necturus kidney is intermediate between the figures for frog skin $\left(0.073 \mathrm{k} \Omega^{-1} \mathrm{~cm}^{-2}\right)$ given by Linderholm (1952) and the results shown in Table III.

"Mannitol" Medium Outside.-The substitution of "mannitol" medium for " $\mathrm{NaCl}$ " medium on the stromal side caused a greater reduction of the total and individual ion conductances than did the " $\mathrm{SO}_{4}$ " medium (Table III), and this, so far as the anions are concerned, suggests that $\mathrm{SO}_{4}$ may contribute to anion conductance. It also appears that the sodium conductances tend to decrease as the external concentration of sodium ion decreases and, insofar as this depends upon the mobility and concentration of sodium ions in the membrane, such an effect would be anticipated. An expression relating ion conductance to the concentrations and activities on each side of a membrane has been derived by Linderholm (1952: equation 1.3.12) from the Nernst-Planck diffusion equation as formulated by Teorell (1951), and on this basis a fall of about 45 per cent. in $G_{p}^{\mathrm{Nd}}$ would be anticipated. However, Linderholm's expression is based on the assumption of a simple $1: 1$ electrolyte on each side of the membrane and makes further approximations in relating activity coefficients to concentrations and hence may give erroneous values under the present conditions.

Membrane Potential.-The values in " $\mathrm{NaCl}$ " medium are comparable with those reported previously (Berggren, 1960; Cole, 1961b), as are also the effects of " $\mathrm{SO}_{4}$ "- and "mannitol"-media on the stromal side. Whilst the membrane P.D. varies considerably from one group of experiments to another, it is noteworthy that the calculated values for active sodium transport potential $\phi_{a}^{\mathrm{Na}}$, and the sodium "pump" potential, $E_{\mathrm{Na}}$, show much less variation from one type of experimental situation to another. This suggests that the composition of the outer (stromal) fluid does not directly affect the sodium transporting system itself but that:

(a) In the case of the " $\mathrm{SO}_{4}$ " medium, it decreases the effective anion 
permeability whilst sodium ions are transported at the same rate as before. Thus the short-circuit current, $I$, representing the net active sodium flux, is unchanged but $\phi$ increases on account of the lessened anion conductance in the presence of sulphate.

(b) In the case of the "mannitol" medium, it reduces the amount of sodium ion available for active transport, the rate of which decreases (decrease of $I$ ). In the presence of this reduced rate of sodium transport, the rate of penetration of anions becomes slower without causing an increase in membrane potential.

It has already been suggested that the low value of the blood-aqueous P.D., as compared with the potential across certain other epithelial structures, may be due to relative high ion conductances. In this situation the actual sodium "pump" potential, $E_{\mathrm{Na}}$, would be diminished in effectiveness by the high value of $\mathrm{G}_{p}^{\mathrm{Na}}$, and it is of interest that the calculated values for $E_{\mathrm{Na}}$ are considerably greater than the observed membrane P.D. (Tables II and III) and do not appear to vary with the sodium or chloride concentration in the external solution. It seems not unreasonable to identify this indication of relatively constant activity with the "driving force" of sodium transport.

The findings are consistent with the view that, during the transport of sodium across the ciliary epithelium, some kind of concentrating process, corresponding to the potential of $30 \mathrm{mV}\left(E_{\mathrm{Na}}\right)$, occurs which might represent the incorporation of sodium ions in a carrier system (e.g. by formation of disodium phosphatidate (Hokin and Hokin, 1960) or by concentration in vacuoles during pinocytosis). $\mathrm{G}_{a}^{\mathrm{Na}}$ would then represent the intracellular mobility of the "sodium carrier" bearing the actively transported fraction of the sodium flux, and $G_{p}^{\mathrm{Na}}$ would represent the movement of free sodium ions across the barrier. In general, high values of $\mathrm{G}_{a}^{\mathrm{Na}}$ would facilitate active transport, whilst high values of $\mathrm{G}_{p}^{\mathrm{Na}}$ would tend to offset it ( $c f$. Linderholm, 1952, p. 106).

When the present values for water and ion influx are compared with the rate of aqueous formation and sodium entrance into the intact eye (Cole, $1960 \mathrm{a} ; 1961 \mathrm{a})$, it is noticeable that, although the membrane potential in these experiments is similar, the net active influx is clearly much lower than in normal eyes. In the intact eye in situ, the blood vessels of the ciliary body appear to be distributed so as to supply the whole of the stromal side of the epithelial layer (Baurmann, 1930), and in the preparation used in the present experiments it is unlikely that the distribution of the bathing media would approach this degree of uniformity. It also appears that the ciliary body has a high blood flow (Meesmann, 1930, 1932; Linnér, 1951, 1952), so that the metabolic requirements of the secretory system are more likely to be effectively supplied in vivo than in vitro. In view of these considerations it is reasonable to regard the isolated preparations as comprising both active and inactive regions of epithelium side by side. In these circumstances the active 
regions will tend to develop a normal membrane potential and the inactive regions, functioning as electrical shunts, will cause the actual potential attained to be less than normal. The amount of current, in the form of sodium ions, conveyed from one side to the other will, however, depend on the proportion of transporting "units" which are active. It is suggested that, on account of its great vascularity, a far larger proportion would be active in the eye in situ than in the in vitro preparation, thus accounting for the difference in influx rates. The isolated epithelium, on account of its regions, can nevertheless serve as a model, illustrating some of the features of transport across the blood-aqueous barrier.

\section{Summary}

The membrane potential (P.D.), electrical resistance, and "short-circuit current" have been measured in isolated ciliary bodies of ox and rabbit in vitro, and the values so obtained have been used to estimate conductances for sodium and chloride ions. The P.D., but not the short-circuit current, was increased when chloride on the stromal side of the ciliary epithelium was replaced by sulphate ion. When both the sodium and chloride on the stromal side were replaced by mannitol, the P.D. and the short-circuit current were decreased.

The observed values (sodium and chloride ions on both sides of the epithelium) were respectively:

For ox eyes

$$
\begin{aligned}
& \text { P.D. }=5 \cdot 53 \pm 0.41 \mathrm{mV}, \\
& \text { Short-circuit current }=46 \cdot 0 \pm 2.9 \mu \mathrm{A} \mathrm{cm} .^{-2} \text {, } \\
& \text { Conductance }=8.63 \pm 0.95 \mathrm{k} \Omega^{-1} \mathrm{~cm}^{-2} \text {, }
\end{aligned}
$$

For rabbit eyes

$$
\begin{aligned}
& \text { P.D. }=3.83 \pm 0.16 \mathrm{mV} \text {, } \\
& \text { Short-circuit current }=29 \cdot 5 \pm 0.42 \mu \mathrm{A} \mathrm{cm} .^{-2} \text {, } \\
& \text { Conductance }=8.09 \pm 0.29 \mathrm{k} \Omega^{-1} \mathrm{~cm} .^{-2}
\end{aligned}
$$

In the rabbit eye the net water flux from the stromal to the neuro-epithelial side of the ciliary body was $0.16 \pm 0.02 \mu 1 . \min .^{-1} \mathrm{~cm} .^{-2}$, which is in good agreement with the value obtained by assuming that the short-circuit current represented the net influx of sodium ions.

Since these findings are consistent with the view that transfer of water and solutes across the ciliary epithelium depends upon the active transport of sodium ions, the active sodium "pump" potential was calculated on the basis of the equations of Linderholm (1952), and amounted to about $30 \mathrm{mV}$ in both ox and rabbit eyes.

The values for sodium conductance are discussed in terms of a hypothetical "sodium carrier". 
It is thought that, on account of the better distribution of solutes and metabolites to the ciliary epithelium which obtains in the eye in its normal condition, in the present experiments in vitro a smaller proportion of the epithelium will have been available for active transport; this would explain the low values observed for influx in the presence of an almost normal blood-aqueous potential difference.

\section{REFERENCES}

Baurmann, M. (1930). Ber. dtsch. ophthal. Ges., 48, 364.

BERGGREN, L. (1960). Acta physiol. scand., 48, 461.

Bertolacini, R. J., and Barney, J. E., II. (1958). Analyt. Chem., 30, 202.

Cole, D. F. (1960a)., Brit. J. Ophthal., 44, 225.

(1960b). Ibid., 44, 739 .

(1961a). Ibid., 45, 202. (1961b). Ibid., 45, 641.

GiebisCH, G. (1960). Circulation, 21, 879. (1961). J. gen. Physiol., 44, 659.

HokIN, L. E., and HokIN, M. R. (1960). Ibid., 44, 61.

KoEfoed-Johnsen, V., and Ussing, H. A. (1956). "Abst. Comm. XX Int. Physiol. Congress, Brussels, 1956", pp. 511-512.

- (1958). Acta physiol. scand., 42, 298.

Leaf, A. (1960). J. gen. Physiol., 43, No. 5 (Suppl.), Pt 2, p. 175. and RENSHAw, A. (1957). Biochem. J., 65, 82.

LINDERHOLM, H. (1952). Acta physiol. scand., 27, Suppl. 97. (1954). Ibid., 31, 36-61.

LINNÉR, E. (1951). Ibid., $22,83$. (1952). Ibid., 26, 70.

MeEsmann, A. (1932). Ber. dtsch. ophthal. Ges., 49, 268. (1930). Ibid., 48, 99.

Robinson, R. A., and Stokes, R. H. (1959). "Electrolyte Solutions”, 2nd ed. Butterworth, London.

TeORell, T. (1951). Z. Elektrochem., 55, 460.

Ussing, H. H. (1960). "In Handbuch der experimentellen Pharmakologie," ed. O. Eichler and A. Farah, vol. 13, pp. 1-195. Springer, Berlin. and ZeraHN, K. (1951). Acta physiol. scand., 23, 110.

Whittembury, G., Sugino, N., and Solomon, A. K. (1961). J.gen. Physiol., 44, 689. 